Egypt. Acad. J. Biolog. Sci., 4(1): 39 -46 (2012)

Email: egyptianacademic@yahoo.com

Received: $20 / 4 / 2012$
B. Zoology

ISSN: $2090-0759$

www.eajbs.eg.net

\title{
Sexual Dimorphism in the Shell Shape of the Golden Apple Snail, Pomacea canaliculata (Lamarck) Using Geometric Morphometric Analysis
}

\author{
Carlo Stephen Moneva, Mark Anthony J. Torres and Cesar G. Demayo
}

Department of Biological Sciences, College of Science and mathematics, MSU-Iligan

Institute of Technology, Iligan City, Philippines

\section{ABSTRACT}

It has been accounted that the extent of sexual dimorphism in Pomacea canaliculata, a serious rice pest in Asia, has caused considerable taxonomic confusion. This study was conducted to explore possible sexual shell dimorphism in $P$. canaliculata by the aid of geometric morphometric measurements, since traditional measurements have problems in terms of accuracy. Relative Warp Analysis and Discriminant Function Analysis have been used in the study to determine patterns of sexual shell dimorphism in the golden apple snail. Results demonstrated sexual differences in size, spire height, and shell opening. These morphological differences could be attributed to ecological responses of the gastropod. The results clearly indicate that geometric morphometric methods are useful in detecting subtle differences between sexes.

Keywords:

\section{INTRODUCTION}

Descriptions of organisms typically include qualitative estimates of body shapes. For the past years, the study of biological form progressed from qualitative to quantitative. New methodological and analytical tools have been developed to facilitate the acquisition, interpretation and presentation of shape data collectively referred to as geometric morphometric (GM) techniques. Analysis of shape differences within, between and among groups of organisms based on anatomical landmarks defined by $\mathrm{x}$ and y Cartesian coordinates. Geometric morphometric (GM) methods accomplish this by comparing the coordinates collected from different specimens after removing the effects of size, position, and orientation, allowing the evaluation of shape differences only (Adams et al., 2004). Image analysis coupled with geometric morphometric has proven important in the quantitative shape analysis of many biological structures. This method of analysis represents scientific opportunity to study taxonomic characters on discriminating between sexes of the golden apple snail, Pomacea canaliculata (Lamarck, 1819) which was found to have a problem in sex differentiation. Sexual dimorphism in this species is traditionally quantified through straight-line measurements and ratios but recently, the tools of geometric morphometric analysis was found to be useful in snail shell dimorphism (Galliguez et al., 2009; Minton and Wang, 2011) thus is used in the current study.

$P$. canaliculata shows remarkable anatomical, physiological and ecological characteristics, which have enthralled scientific, interest since long ago (Estebenet and Martin, 2002). It received much attention when it became established as a serious rice pest in Asia including the Philippines (Cowie, 2006; Cagauan and Joshi, 2003; Joshi et al., 2005; and Joshi, 2005; Guerrero, 1989). Sex differences in this species were originally determined by looking at the sizes. Females are significantly larger than 
males (Cazzaniga, 1990; Estebenet and Cazzaniga, 1998). The extent of dimorphism however may vary among populations thus caused considerable nomenclatural and taxonomic confusion (Cowie, 2006). This study was therefore conducted to quantitatively describe sexual dimorphism in the shell shape of $P$. canaliculata based on its shell (apertural/ventral, dorsal, whorl/top) shape patterns. Examination of the shell shape variation was made using geometric morphometry.

\section{MATERIAL AND METHODS}

The golden apple snails ( $P$. canaliculata) were obtained from Ozamis City and Plaridel, Misamis Occidental. A total of 60 specimens were utilized comprising of 30 females and 30 males for each population. Map showing the study area is shown in (Fig.1).

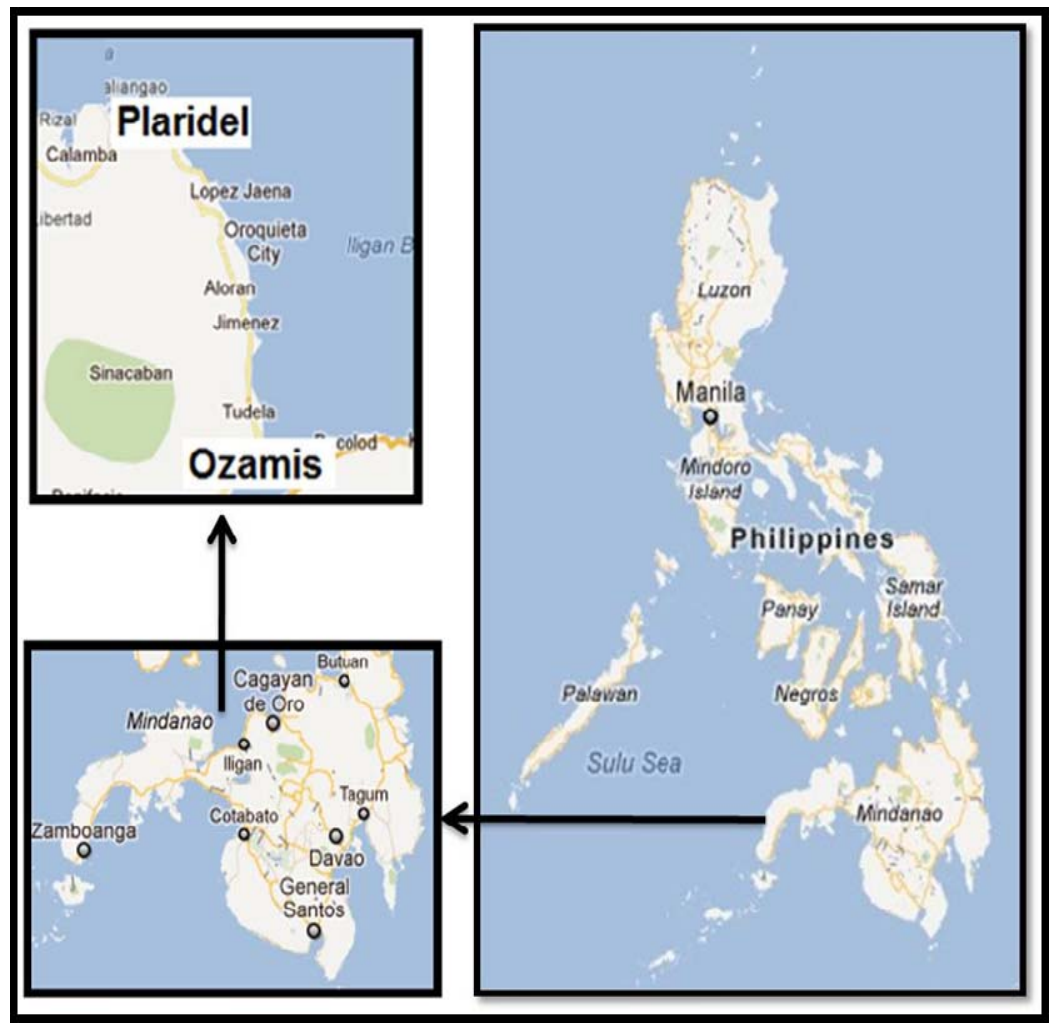

Fig. 1: Map showing the study area, Ozamis City and Plaridel, Misamis Occidental, Philippines.

Shells were photographed by a digital camera. Images of the shell were in the same position with the columella at $90^{\circ}$ of the $\mathrm{x}$-axis in an aperture view or in the orientation in which the apex is visible. Obtained images were then subjected to geometric morphometric methods. Digital images (ventral, dorsal and top view) were taken for each sample using a standardized procedure (Fig. 2). The shell of the apple snail is spherical or heliciform or elongate ovate shell form having three to five sutures with wide oval or circular aperture. It has no siphonal canal and the outer lip of the aperture is not reflected.

Shell shape was studied using a landmark-based methodology that eliminates the effect of variation in the location, orientation, and scale of the specimens. Twenty one anatomical landmarks located along the outline of the ventral/apertural (Fig. 2a) portion of the shell and seventeen anatomical landmarks along the dorsal (Fig. 2b) 
portion of shell were defined and used. Obtained digitized images of the snail's shell were then outlined with sample points around its contour in order to get the $\mathrm{x}$ and $\mathrm{y}$ coordinates. This was made possible using an image analysis and processing software tps Dig freeware 2.12 which facilitates the statistical analysis of landmark data from digitized images (Rohlf, 2008a).

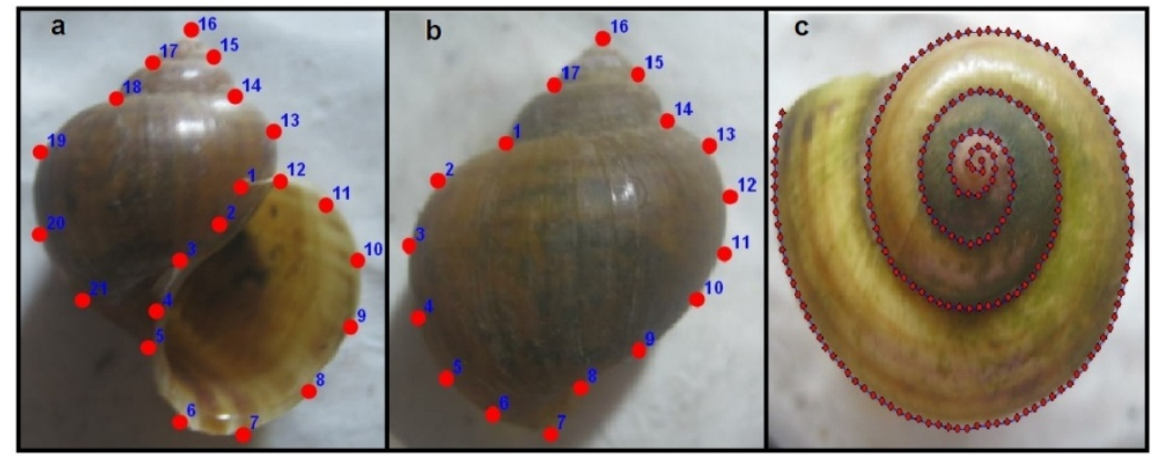

Fig. 2: Landmarks used to describe the shape of the (a) ventral, (b) dorsal, and (c) top view of the shell of $P$. canaliculata.

The coordinates were transferred to Microsoft Excel application for organization of the data into groups (based on species). The two-dimensional coordinates of these landmarks were determined for each shell specimen. Then the generalized orthogonal least squares Procrustes average configuration of landmarks was computed using the generalized Procustes Analysis (GPA) superimposition method. GPA was performed using the software tpsRelw, ver. 1.46 (Rohlf, 2008b). After GPA, the relative warps (RWs, which are the principal components of the covariance matrix of the partial warp scores) were computed using the unit centroid size as the alignment-scaling method. Histogram and box plots were generated using PAST software (Hammer et al., 2009) from the relative warps of the shell shapes. Histogram and box plots are powerful displays for comparing distributions. They provide compact view of where the data are centered and how they are distributed over the range of the variable. Kruskal-Wallis test was used to analyze whether or not the species differ significantly with regards to its shell shape (Demayo et al., 2011).

The top or whorl (Fig. 2c) portion of the shell were outlined with 199 outline points using tpsDig program and the tps curve outline was converted to landmarks (corresponding $\mathrm{x}$ and $\mathrm{y}$ ) using tpsUtil ver.1.44 (Rohlf, 2009). The collective coordinates of all individuals were then subjected to different multivariate analyses, which include Principal Component Analysis (PCA), Elliptic Fourier Analysis (EFA), and Discriminant Function Analysis (DFA) using the Paleontological Statistics (PAST) software developed by Hammer et al. (2009). PCA was used to summarize the information of the variations and mean shapes contained in the coefficients of landmark descriptors. The shapes of snail's shell were also compared using the method (EFA). The Fourier coefficients were then used as variables for another multivariate method of statistical analysis in the form of DFA.

\section{RESULTS AND DISCUSSION}

The summary of the geometric morphometric analysis showing the consensus morphology (ventral/apertural and dorsal portion) of the golden apple snail is shown in Fig. (3). Descriptions of the overall shape variation in the ventral/apertural and 
dorsal shell of the golden apple snails were shown in Table (1). Projections on the left and right sides of the histogram are considered to be variations in shell shape.

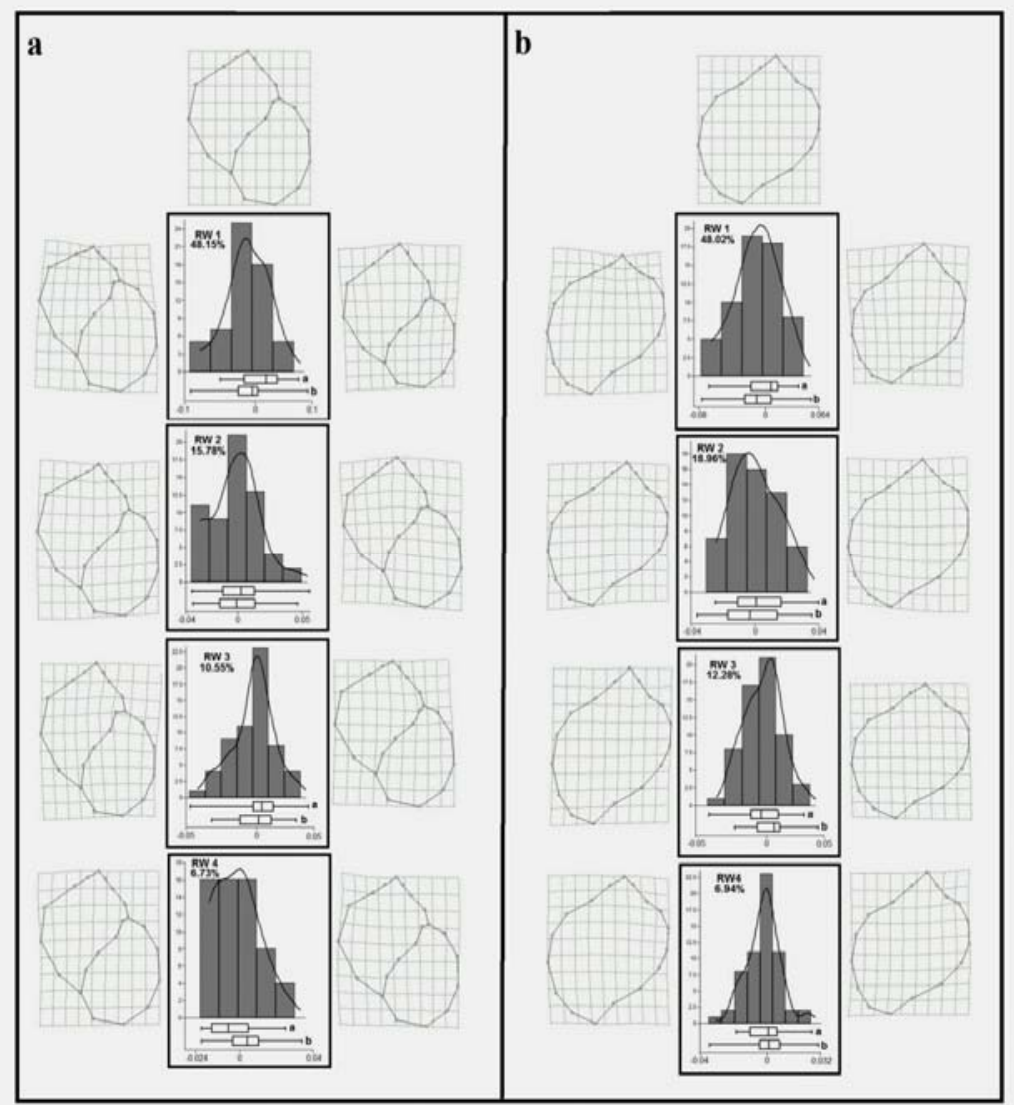

Fig. 3: Summary of geometric morphometric analysis showing consensus morphology and variation in (a) ventral/apertural and (b) dorsal shell of P. canaliculata as produced by Relative Warps.

Table 1: Percentage variance and overall shape variation in the ventral/apertural and dorsal shell of $P$. canaliculata as explained by significant relative warps.

\begin{tabular}{|c|c|c|c|c|}
\hline RW & $\begin{array}{c}\% \\
\text { variation }\end{array}$ & Ventral/apertural shell & $\begin{array}{c}\% \\
\text { variation }\end{array}$ & Dorsal shell \\
\hline 1 & $48.15 \%$ & $\begin{array}{l}\text { The first relative warp axis (RW1) describes } \\
\text { differences in the shape of the shell opening. A high } \\
\text { positive RW1 score means that a shell has less } \\
\text { pronounced and narrower shell opening in contrast to } \\
\text { the more globose shell opening of the samples along } \\
\text { low negative RW } 1 \text { score. Golden apple snails between } \\
\text { sexes are at either positive or negative RW1 axis } \\
\text { signifying that these populations have either wide or } \\
\text { narrow aperture. }\end{array}$ & $48.02 \%$ & $\begin{array}{l}\text { The first relative warp illustrates the } \\
\text { differences in the height of the spire and } \\
\text { the shell. Samples found in the negative } \\
\text { RW } 1 \text { axis have the characteristics of a } \\
\text { short but more pronounced apical spire. } \\
\text { On the other hand, a more elevated but } \\
\text { less pronounced apical spire was } \\
\text { illustrated on the positive RW1 axis. }\end{array}$ \\
\hline 2 & $15.78 \%$ & $\begin{array}{l}\text { The second relative warp axis (RW2), which attributed } \\
\text { to differences in the body whorls. A low negative RW2 } \\
\text { score means that a shell has a broader and more } \\
\text { pronounced body whorl. Furthermore, a sample with a } \\
\text { high positive RW2 score has shell with narrower and } \\
\text { less pronounced body whorl. }\end{array}$ & $18.96 \%$ & $\begin{array}{l}\text { RW2 explains differences in the } \\
\text { posterior margin of the outer dorsal lip } \\
\text { or the differences in the basal portion of } \\
\text { the dorsal shell. }\end{array}$ \\
\hline 3 & $10.55 \%$ & $\begin{array}{l}\text { Relative warp three illustrates distinction in the height } \\
\text { of the spires located in the apical portion of the shell. } \\
\text { Samples along the negative axis have a highly elevated } \\
\text { spire compared to samples the along positive RW } 4 \\
\text { axis, which has shorter spires. }\end{array}$ & $12.28 \%$ & $\begin{array}{l}\text { The RW3 describes differences in the } \\
\text { apical spires. Samples with low negative } \\
\text { RW3 score have shell with less } \\
\text { pronounced apex leading to shorter spire } \\
\text { height, while high positive RW3 score } \\
\text { has more pronounced apex. }\end{array}$ \\
\hline 4 & $6.73 \%$ & $\begin{array}{l}\text { Lastly, fourth relative warp (RW4) accounts for the } \\
\text { total shape variation. It has been observed that females } \\
\text { draw toward the negative axis while males towards the } \\
\text { positive axis. }\end{array}$ & $6.94 \%$ & $\begin{array}{l}\text { RW4 suggests that populations of the } \\
\text { opposite sex are concentrated towards } \\
\text { the mean shape and are unimodal in } \\
\text { distribution. }\end{array}$ \\
\hline
\end{tabular}


The topmost figure is the mean shape of the samples obtained. Table (2) shows the results of the Kruskal-Wallis test for significant differences in mean shapes of the ventral/aperture and dorsal shell portion.

Table 2: Results of the Kruskal-Wallis test for significant differences in the mean shapes of $P$. canaliculata ventral/apertural and dorsal shell of $P$. canaliculata.

\begin{tabular}{|c|c|c|c|}
\hline \multirow[b]{2}{*}{ Relative Warp } & \multicolumn{3}{|c|}{ Ventral/aperture } \\
\hline & Sex & $\mathbf{a}$ & b \\
\hline \multirow[t]{2}{*}{1} & (a) female & & 0.07852 \\
\hline & (b) male & 0.07852 & \\
\hline \multirow[t]{2}{*}{2} & (a) female & & 0.9058 \\
\hline & (b) male & 0.9058 & \\
\hline \multirow[t]{2}{*}{3} & (a) female & & 0.3478 \\
\hline & (b) male & 0.3478 & \\
\hline \multirow[t]{3}{*}{4} & (a) female & & 0.01988 \\
\hline & (b) male & 0.01988 & \\
\hline & \multicolumn{3}{|c|}{ Dorsal } \\
\hline Relative Warp & Sex & $\mathbf{a}$ & b \\
\hline \multirow[t]{2}{*}{1} & (a) female & & 0.2643 \\
\hline & (b) male & 0.2643 & \\
\hline \multirow[t]{2}{*}{2} & (a) female & & 0.379 \\
\hline & (b) male & 0.379 & \\
\hline \multirow[t]{2}{*}{3} & (a) female & & 0.1785 \\
\hline & (b) male & 0.1785 & \\
\hline \multirow[t]{2}{*}{4} & (a) female & & 0.525 \\
\hline & (b) male & 0.525 & \\
\hline
\end{tabular}

The shapes of the whorls in the topmost portion of the shells of $P$. canaliculata were also observed and described using outlines assigned in the sutures. Outline coefficients $(\mathrm{N}=199)$ were calculated and interpreted using multivariate Principal Component Analysis (PCA). Fig. (4) illustrates the mean shell shape (top/whorl portion) of $P$. canaliculata (a) female and (b) male. The first and second principal components (PC1 and PC2) provided a good summary of the variation for the top/whorl portion of the shell. PC1 and PC2 for both the female and male top/whorl portion of the shell accounted for more than $85 \%$ and $88 \%$ of the total variance respectively, as presented in Table (3).

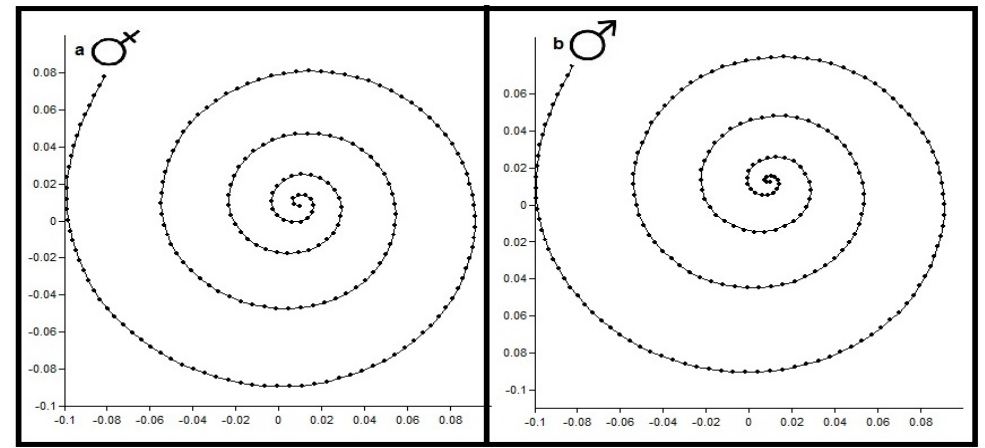

Fig. 4: Principal deformations from the mean shape of P. canaliculata top/whorl shell: (a) female and (b) male.

Table 3: Percentage variance values of the significant components in the top/whorl portion of the shell of $P$. canaliculata.

\begin{tabular}{ccccc}
\hline \hline \multirow{2}{*}{ Principal Components } & \multirow{2}{*}{ Eigen-value } & Variance (\%) & Eigen-value & Variance (\%) \\
& & & 0.020112 & 82.43 \\
PC1 & 0.0165252 & 72.487 & 0.001414 & 5.7964 \\
PC 2 & 0.002846 & 12.695 & & 88.2264 \\
\hline \hline
\end{tabular}


To test whether sexual dimorphism based on the shell shape (ventral/apertural, dorsal, and top/whorl portion) pattern is statistically significant Discriminant Function Analysis (DFA) was performed. Fig. (5) graphically showed the frequency histogram of the degree of sexual dimorphism of P. canaliculata. Illustrated in Table (4) are the percent correctly classified data based on the discriminant function scores of the three characters examined. Results in Table (4) have shown that there are more than 86\%, $90 \%$ and $88 \%$ correctly classified discriminant function scores for both the ventral/aperture ( $80 \%$ of females; $93.33 \%$ of males), dorsal view ( $86.67 \%$ of females; $93.33 \%$ of males) and top/whorl (96.67\% of females; $80 \%$ of males). These results indicate sexual dimorphism in $P$. canaliculata based on the three characters.

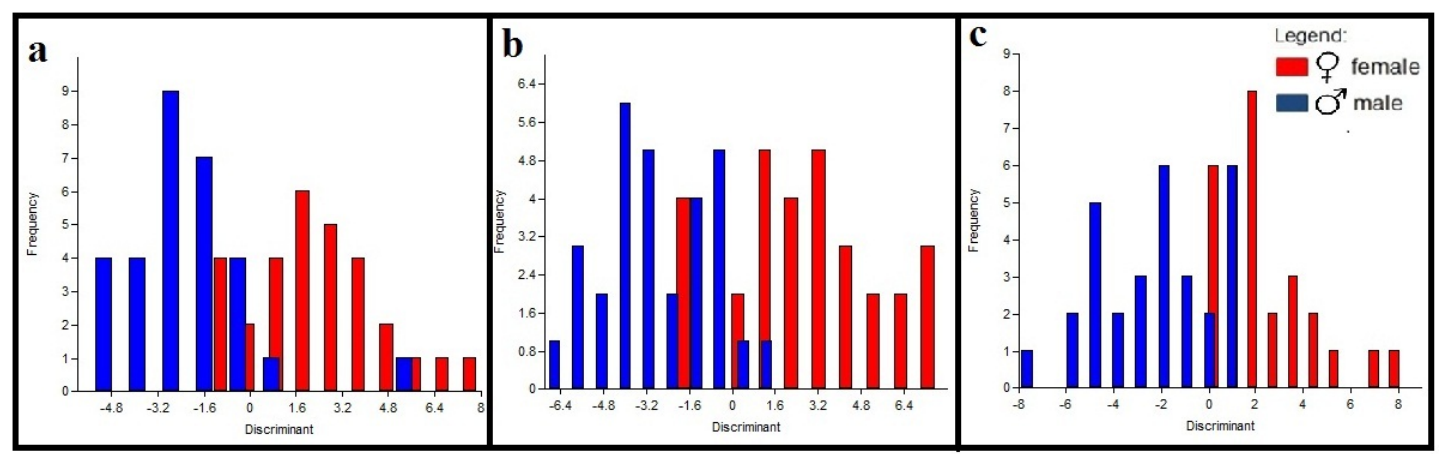

Fig.5: Frequency distribution histogram showing the variation in the (a) ventral/apertural portion, (b) dorsal portion, and (c) top/whorl portion in the shell pattern of the female (red) and male (blue) of $P$. canaliculata.

Table 4: Proportion of variation with the discriminant function scores of the ventral/apertural, dorsal, and top/whorl portion of the P. canaliclata shell.

\begin{tabular}{|c|c|c|c|c|c|c|c|c|c|}
\hline \multirow[b]{3}{*}{$\mathrm{F}$} & \multicolumn{3}{|c|}{$\begin{array}{c}\text { VENTRAL/APERTURAL } \\
\text { SHELL }\end{array}$} & \multicolumn{3}{|c|}{ DORSAL SHELL } & \multicolumn{3}{|c|}{ TOP/WHORL SHELL } \\
\hline & $\mathrm{F}$ & $\mathrm{M}$ & CC (\%) & $F$ & $\mathrm{M}$ & CC (\%) & $F$ & $\mathrm{M}$ & CC (\%) \\
\hline & 24 & 6 & 80 & 26 & 4 & 86.67 & 29 & 1 & 96.67 \\
\hline \multirow[t]{3}{*}{ M } & 2 & 28 & 93.33 & 2 & 28 & 93.33 & 6 & 24 & 80 \\
\hline & Total & & 86.67 & \multicolumn{2}{|c|}{ Total } & 90 & \multicolumn{2}{|c|}{ Total } & 88.33 \\
\hline & $\begin{array}{l}\text { H t2: p } \\
\text { (same) }\end{array}$ & & 0.3076 & \multicolumn{2}{|c|}{$\begin{array}{l}\text { H t2: p } \\
\text { (same) }\end{array}$} & 0.06592 & \multicolumn{2}{|c|}{$\begin{array}{l}\mathrm{H} \mathrm{t2:} \mathrm{p} \\
\text { (same) }\end{array}$} & - \\
\hline
\end{tabular}

Legend: F= Female, M= Male, CC= Correctly classified, H t2= Hotelling’s t2.

Based upon the results, variations between sexes of $P$. canaliculata can be due to differences in the height of the spire and differences in shell opening. The height of the spire is related to the gastropod's natural response for survival (Borra, 2006). Differences in the shape of the shell opening could be attributed to predatory defense of the snail. The shape of the shell opening or the aperture is the best way to prevent shell entry as frequently performed by predators such as decapods (DeWitt, 2000). Narrow apertures are a potentially important defense in freshwater. Conversely, wider aperture indicates vulnerability to predation (Williams, 2005). It could be inferred that predators may affect apertural shape of the freshwater snails.

Sexual dimorphism in $P$. canaliculata has been inferred on size differences where females are larger than males (Estebenet and Cazzaniga, 1998). In addition to size dimorphism, qualitative analysis revealed that there appears to be variation in the shape of the aperture and operculum where females have broader mouth and a concave operculum and the males a convex operculum (Cowie, 2006). Since the 
operculum is located in the opening or the apertural portion of the shell it is argued to be affecting its over-all shape patterns.

The results of the current study suggest the presence of sexual dimorphism in $P$. canaliculata applying the quantitative methods of geometric morphometrics. These methods are effective in the determination of sexual dimorphism in the shell shape of $P$. canaliculata. The applications of GM tools are efficient in quantitatively describing shape variations and differentiate between sexes of $P$. canaliculata. Describing sex differences in the snail's shell using various characters like the ventral/aperture, dorsal, and top/whorl portion quantitatively are efficiently done using GM analysis. This study indicates that geometric morphometric methods are useful in detecting subtle differences between sexes and to understand the patterns of shell shape variation and can be used to advance taxonomic and micro-evolutionary studies of gastropods. Further studies using correlation of different shell shape characters is highly recommended in order to determine sexual shell dimorphism in gastropods.

\section{REFERENCES}

Adams, D.C., Rohlf, J.F. and Slice, D.E. (2004). Geometric morphometrics: ten years of progress following the "revolution'. Italian Journal of Zoology, 71: 5-16.

Borra, R.G. (2006). Geometric Morphometric and Qualitative Analysis of the shell in some collected species of marine, freshwater and land snails. A Master's Thesis. School of Graduate Studies, MSU-IIT, Iligan City.

Cagauan, A.G. and Joshi, R.C. (2003). Golden apple snail Pomacea spp. in the Philippines. Review on levels of infestation, control methods, utilization and future research directions. J. Agriculture and Life Sciences, 37(2): 7-32.

Cazzaniga, N.J. (1990). Sexual dimorphism in P. canaliculata. Veliger, 33: 384-38.

Cowie, R.H. (2006). Apple snails as agricultural pests: their biology, impacts, and management. $\quad$ Retrieved April 20, 2011 from http://www.cdfa.ca.gov/phpps/ppd/Entomology/Snails/AMPchap.htm.

Demayo, C.G., Harun, S.A. and Torres, M.A.J. (2011). Procrustes Analysis of Wing Shape Divergence among sibling species of Neurothemis Dragonflies. Australian Journal of Basic and Applied Sciences, 5(6): 748-759.

DeWitt, T.J. (2000). Functional diversity among predators of a freshwater snail imposes an adaptive trade-off for shell morphology. Evolutionary Ecology Research, 2: 129-148.

Estebenet, A.L. and Cazzaniga, N.J. (1998). Sex related differential growth in $P$. canaliculata (Gastropoda: Ampullariidae). J. Moll. Studies, 64: 119-123.

Estebenet A.L. and Martin, P.R. (2002). P. canaliculata (Gastropoda: Ampullariidae): Life-history Traits and their Plasticity. BIOCELL, 26(1): 83-89.

Galliguez, E.M., Torres, M.A.J. and Demayo, C.G. (2009). Modularity and Integration in the Shape of the shell of Vivipara angularis Muller (Architaenioglossa: Viviparidae). Journal of Nature Studies, 8(2): 51-58.

Guerrero, L. (1989). The Biology of Golden Snail in Relation to Philippine Conditions. Aquatic Biosystems, National Highway, Bay, Laguna. Phil. Summary Report of the workshop held at the Freshwater Aquaculture Center, Central Luzon State University, Nueva Ecija, Philippines.

Hammer, O., Harper, D.A.T. and Ryan, P.D. (2009). PAST version 1.91: Paleontological Statistical Software package for education and data analysis. Paleontologia Electronica, 4(1): 9pp. 
Joshi, R.C. (2005). Managing invasive alien mollusc species in rice. Dept. of Agriculture- Philippine Rice Research Institute (DA-PhilRice), Maligaya, Science City of Munoz, Nueva Ecija, 3119, Philippines. IRRN, 30.2

Joshi, R.C., Martin, A.R. and Sebastian, L.S. (2005). Off-season survival of golden apple snails in the Philippines. Philippine Rice Research Institute (PhilRice), Maligaya, Science City of Munoz, Nueva Ecija 3119, Philippines. IRRN, 30.1. Minton, R.L. and Wang, L.L. (2011). Evidence of Sexual Shape Dimorphism in Viviparus (Gastropoda: Viviparidae). Journal of Molluscan Studies, 0: 1-3.

Rholf, J.F. (2008a). tpsDig program. Ecology and Evolution, SUNY at Stony Brook.

Rohlf, J.F. (2008b). Relative Warps version 1.46. Ecology and Evolution, SUNY at Stony Brook.

Rohlf, J.F. (2009). tps Utility program version 1.44. Ecology and Evolution, SUNY at Stony Brook.

Williams, P. (2005). What does the snail shell tell? Accessed at www.shelltrips.com. 